\title{
Correspondence
}

\section{Apnea after spinal anesthesia}

To the Editor:

We have concerns about the report by Tobias concerning apnea after spinal anesthesia. ${ }^{1}$ There have been no reports of postoperative apnea following an uncomplicated spinal anesthetic in infants not receiving supplemental sedation or narcotic analgesia. Both infants described by Tobias had episodes of apnea within minutes of administration of a subarachnoid block. The authors state the sensory level of the block was T6, although the level is difficult to determine in infants. The amount of tetracaine used seems excessive: both infants received $1.0 \mathrm{mg} \cdot \mathrm{kg}^{-1}$. Most experience settles on an average dose of $0.5 \mathrm{mg} \cdot \mathrm{kg}^{-1} .^{2}$

In the second infant, no details of the length of apnea or degree of bradycardia are presented. Although definitions vary, apnea is generally defined as an episode of cessation of airflow for $15-20 \mathrm{sec}^{3}$ Furthermore, infants have episodes of bradycardia and periodic breathing associated with feeding and defecation. Choking, gagging and gastroesophageal reflux are also known to cause bradycardia and apnea while feeding. It seems a stretch of the definition to attribute this episode associated with feeding to a spinal anesthetic eight hours previously.

Spinal blockade can extend further than intended in any patient including infants and adults. However, intraoperative apnea and respiratory insufficiency associated with a high block must be differentiated from postoperative apnea occurring after the infant has recovered from the block and is ready for discharge home or the ward.

Robert K. Williams MD

J. Christian Abajian MD

Burlington, Vermont, U.S.A.

References

1 Tobias JD, Burd RS, Helikson MA. Apnea following spinal anaesthesia in two former pre-term infants. Can J Anaesth 1998; 45: 985-9.

2 Williams RK, Abajian JC. Infant spinal anesthesia. In: Busoni P (Ed.). Techniques in Regional Anesthesia and Pain Management. Philadelphia: W.B. Saunders Co, 1999.
3 Ariagno RL. Apnea of prematurity. In: Burg FD, et al (Eds.). Current Pediatric Therapy 16th ed.

Philadelphia: W.B. Saunders Co, 1999: 325-6.

\section{REPLY:}

I disagree with Drs. Williams and Abajian's contention that our patients do not meet the definition of apnea following uncomplicated spinal anesthesia. I fail to see how the apnea could have been the result of high motor block. Both infants cried immediately and moved their upper extremities with stimulation when the apneic episode was detected. The intermittent nature of the apnea and respiratory insufficiency argues against a high level of motor blockade. While the limited information supports tetracaine doses of 0.4-0.6 $\mathrm{mg}^{-\mathrm{kg}^{-1}}$ in infants, my experience over the past ten years in over 200 infants has been with doses of 0.6-1 $\mathrm{mg} \cdot \mathrm{kg}^{-1}$. Abajian et al. have used tetracaine doses up to 0.65-0.7 $\mathrm{mg}^{\mathrm{kg}}{ }^{-1}$ without adverse effects. ${ }^{1,2}$

The first infant had the respiratory event with choking and gagging during feeding, eight hours postoperatively. I agree that this was not the result of the spinal anesthetic. We contend that events that occurred immediately following the placement of the spinal block and during the next one to two hours are the result of the spinal anesthetic. Both infants displayed apnea with cessation of respiratory efforts for more than 15-20 sec associated with a decrease in heart rate and oxygen saturation.

Despite the possible role of spinal anesthesia in the perioperative apnea experienced by these two infants, we still feel that spinal anesthesia offers a safe and effective alternative to general anesthesia in infants and children.

Joseph D. Tobias MD

Columbia, Missouri, USA

References

1 William RK, McBride WJ, Abajian JC. Combined spinal and epidural anaesthesia for major abdominal surgery. Can J Anaesth 1997; 44: 511-4.

2 Viscomi CM, Abajian JC, Wald SL, Rathmell JP, Wilson $J T$. Spinal anesthesia for repair of meningomyelocele in neonates. Anesth Analg 1995; 81: 492-5. 